\title{
PANCASILA DAN SYARIAT ISLAM
}

Ali Geno Berutu

ali_geno@ymail.com

Pada awal kemerdekaan Indonesia terjadi tarik-menarik kepentingan antara banyak ideologi perihal kedudukan agama dalam negara. Walaupun ummat Islam di Indonesia adalah penduduk mayoritas, tapi hal ini bukan berarti penetapan Islam sebagai dasar negara menjadi sesuatu yang mudah dilakukan, hal ini disebabkan karena ummat Islam Indonesia tidak semuanya sepakat tentang apa yang seharusnya dilakukan pemeluk Islam di Indonesia, setidaknya inilah alasan yang dikemukakan oleh Fred Von Den Mehden. ${ }^{1}$

Proses awal pembentukan negara Indonesia dihadapkan pada persoalan yang sangat krusial yakni kesepakatan mengenai dasar negara. ${ }^{2}$ Dalam sidang BPUPKI (Badan Penyelidik Usaha Persiapan Kemerdekaan Indonesia), permasalahan pokok yang dibicarakan adalah mengenai bentuk dan dasar filsafat negara yang bertalian dengan pembuatan konstitusi. ${ }^{3}$ Pertarungan ideologi yang melibatkan kelompok nasionalis - Islam dan nasionalis - sekuler dalam Piagam Jakarta. Perdebetanpun terjadi mengenai kosnsep dasar negara bangsa dan dasar negara Islam. ${ }^{4}$ Dasar negara kebangsaan diusung oleh tokoh-tokoh seprti, Soekarno, Muhammad Hatta, Muhammad Yamin, Soepomo. Sedangkan utuk kalangan yang mendukung Islam sebagai dasar negara direpresentasikan oleh tokoh-tokoh seperti, KH. Wachid Hasjim, Ki Bagoes Hadikoesoemo dan Kahar Muzakkir.

Sidang pertama BPUPKI dilakukan dengan rentang waktu 29 Mei - 1 Juni 1945, pada sidang ini terjadi perdebatan yang sengit, dimana kelompok nasionalis - Islamis menghendaki agar Islam dijadikan sebagai dasar negara, sedangkan kelompok nasionalis sekuler tidak setuju dengan gagasan tersebut, dan lebih berpandangan pada pemisahan agama dan negara. Perdebatan yang panas dan tajam mengenai dasar negara pada akhirnya menghasilkan sebuah kompromi pada tanggal 22 Juni dalam bentuk rumusan yang dikenal dengan "Piagam Jakarta". Piagam Jakarata tesebut merupakan hasil kerja tim yang diketuai oleh Soekarno dengan anggota tim yakni, Muhammad Hatta, A.A. Maramis, Abikusno Tjokrosujoso, Abdulkahar Muzakkir, Agus Salim, Ahmad Subarjo, Wachid Hasjim dan Muhammad Yamin. Pada rumusan Piagam Jakarta telah disepakati bahwa Pancasila sebagai dasar negara dengan sila pertama yaitu ketuhan "dengan kewajiban menjalankan syariat Islam bagi pemeluk-pemeluknya”. Tujuh kata dalam Piagam Jakarta tesebut juga disepakati masuk kedalam rumusan naskah konstitusi dasar negara Republik Indonesia yang akan diproklamasikan.

Setelah Proklamasi kemerdekaan Indonesia dilakukan pada 17 Agustus 1945 masalah baru tibul kembali, yakni adanya keberatan dari kelompok agama minoritas mengenai tujuh kata dalam piagam Jakarta. Kelompok minoritas yang berasal dari Indonesia Timur ${ }^{6}$ seperti Bali, Maluku, Plores dan Sulawesi mengancam tidak akan mau bergabung dengan Indonesia

${ }^{1}$ Fred von den Mehden, Religion and Modernization in South East Asia (Syracuse: Syracause University Press, 1986), 184.

${ }^{2}$ Saifuddin Anshari, "The Jakarta Charter of June 1945: A History of the Gentleman's Agreement between the Islamic and the Secular Nationalists in Modern Indonesia” (Tesis: Institute of Islamic Studies, McGill University, 1976), 2.

${ }^{3}$ Yuni Roslaili, formalisasi Hukum Pidana Islam di Indonesia....., 71.

${ }^{4}$ Widy Rossani Rahayu, "Perdebatan Tentang Dasar Negara Pada Sidang Badan Persiapan Usahausaha Penyelidikan Kemerdekaan (BPUPK): 29 Mei-17 Juli 1945”(Skripsi Fak. Ilmu Pengetahuan Budaya UI, 2008), 95.

${ }^{5}$ Haidar Nassir, Islam Syariat Reproduksi Salafiyah Idiologis di Indonesia,....240.

${ }^{6}$ Khairullah Zikri, "The Jakarta Charter and the Construction of Indonesian Identity", En Arche, Indonesian Journal of Inter-Religious Studies, Vol. 1, No. 2 (2012), 109. 
jika tujuh kata dalam Piagam Jakarta tetap dimasukkan ke dalam Preambule UUD $1945 .^{7}$ Melalui perdebatan yang panjang mengenai pro dan kontra tentang penghapusan tujuh kata dalam Piagam Jakarta, akhirnya dalam pertemuan yang mendadak yang dimotori oleh Soekarno dan Muhammad Hatta, beberapa saat sebelum sidang PPKI dilakukan pada 18 Agustus 1945, terjadi penghapusan tujuh kata dalam Piagam Jakarta untuk pembukaan UUD 1945.

Kompromi politikpun terjadi antara Muhammad Hatta yang mewakili kalangan nasionalis dengan Kasman Singodimedjo yang mewakili dari kalangan Islam, kompromi politik tersebut diambil guna untuk menjaga keutuhan Negara Kesatuan Republik Indonesia yang saat itu baru berusia satu tahun. ${ }^{8}$ Kalangan Islam pada akhirnya menyetujuai perubahan tujuh kata dalam Piagam Jakarta "dengan kewajiban menjalankan syariat Islam bagi pemeluk-pemeluknya" dirubah menjadi "Ketuhanan Yang Maha Esa”. Dalam sidang pada 18 Agustus 1945, PPKI mensahkan UUD 1945 sebagai dasar konsitusi Indonesia dan mengakhiri perdebatan dan perselisihan mengenai dasar negara Indonesia.

Reformasi telah membuka jalan bagi demokrasi dan sekaligus Islamisasi di Indonesia. Salah satu produk dari demokrasi tersebut adalah otonomi daerah yang dimana sangat memperngaruhi proses - Islamisasi di Indonesia. Pada era reformasi ini telah membuka jalan bagi kelompok Islam yang lebih beragam untuk memperjuangkan aspirasi Islam mereka yang sebulumnya mengendap. Seperti Forn Pembela Islam (FPI), Laskar Jihad (LJ), Forum Komunikasi Ahlus - Sunnah wal-Jama'ah (FKAWJ), Majelis Mujahdin Indonesia dan lain-lain. ${ }^{9}$ Gerakan ini mencoba memperjuangkan terwujudnya masyarakat Indonesia yang lebih Islami dengan mengkampanyekan gerakan "amar ma'rüf nahy $\bar{i}$ munkar”. Dari kalangan partai politik juga ikut mengupayakan formalisasi syariat Islam di Indonesia, seperti partai Bulan Bintang (PBB) dan Partai Persatuan Pembangunan (PPP), dalam sidang tahunan MPR 2002 untuk mengamandemen ${ }^{10}$ pasal 29 UUD 1945 dengan memasukkan tujuh kata dalam Piagam Jakarta "dengan kewajiban menjalankan syariat Islam bagi pemeluk-pemeluknya" dengan alasan agar formalisasi syariat Islam mempunyai landasan konstitusi yang jelas di Indonesia. ${ }^{11}$ Tapi pada akhirnya usaha ini juga kandas karena tidak mendapat dukungan mayoritas diparlemen ${ }^{12}$.

Yang menarik dalam hal ini adalah dua organisasi masyarakat Islam terbesar di Indonesia yakni Nahdatul Ulama (NU) dan Muhammadiyah tidak mendukung dilakukan perubahan terhadap pasal 29 UUD 1945, hal ini dilakukan guna untuk menghindari terjadinya perdebatan dan perselihan diantara masyarakat indonesia. Sebagaimana di ungkapkan oleh Hasim Muzadi dari kalangan NU bahwa perjuangan untuk menegakkan syariat Islam di Indonesia tidak realistis, dia mendesak supaya mengedepankan nilai-nilai universal demi kemakmuran rakyat dan bukan mendorong gagasan syariat Islam untuk diterapkan di Indonesia, senada dengan Hasim, Syafi'i Ma'arif dari kalangan Muhammadiyah mengatakan bahwa kita harus berkomitmen untuk mengutamakan

\footnotetext{
${ }^{7}$ Saifuddin Anshari, "The Jakarta Charter of June 1945:........., 66.

${ }^{8}$ Haidar Nassir, Islam Syariat Reproduksi Salafiyah Idiologis di Indonesia,....241

9 Sukron Kamil dkk, Syariah Islam dan HAM: Dampak Perda Syariah Terhadap Kebebasan Sipil, Hak-Hak Perempuan dan Non-Muslim (Ciputat:CSRS UIN Jakarta, 2007), 108-109.

${ }^{10}$ Khairullah Zikri, "The Jakarta Charter and the Construction of Indonesian Identity...,111.

${ }^{11}$ Yusnadi, "Formalisasi Syariat Islam dan Hak Asasi Manusia di Indonesia", Al-Mawarid, edisi XVI tahun 2006, 192.

${ }^{12}$ Nadirsyah Hosen, "Religion and the Indonesian Constitution: A Recent Debate", Journal of Southeast Asian Studies, pp 419-440 October 2005, $427 . \quad \underline{\text { http://journals. }}$ Cambridge.org/abstract_S0022463405000238 (diakses pada tanggal 9 Juli 2014). Lihat juga Arskal Salim \& Azyumardi Azra, 'Introduction: the State and Shari'a in the perspective of Indonesian Legal Politics, "Shari'a and Politics in Modem Indonesia, ed. Arskal Salim \& Azyumardi Azra, (Singapore: Institute of Southeast Asian Studies, 2003), 1.
} 
persatuan dan kesatuan bangsa Indonesia sebagaimana yang diamanatkan oleh pendiri bangsa ini. ${ }^{13}$ Anis Baswedan menjelaskan bahwa fokus ummat Islam sekarang ini bukanlah menjadikan Islam sebagai dasar negara Indonesia, tetapi bagaimana membawa warna Islam itu sendiri kedalam kedalam kebijakan yang dihasilkan oleh parlemen, inilah menurutnya yang menjadi pendekatan syariah yang dilakukan oleh kedua ormas tersebut (NU Muhammadiyah).

Muhammad Mahfud MD dalam pengantar buku Syarah Konstitusi Dalam Perspektif Islam karangan Masdar Farid Mas'udi menjelaskan bahwa, Indonesia dengan dasar Pancasila dan UUD 1945 merupakan suatu negara yang islami, tetapi bukan negara Islam. Negara islami yang dimaksud Mahfud adalah negara yang secara resmi tidak menggunakan nama dan simbol-simbol Islam akan tetapi subtansinya mengandung nilai-nilai ajaran Islam. Seperi kepemimpinan yang adil, amanah, domokratis, menghormati hak asasi manusia dan lain sebagainya. ${ }^{14}$ Pemilihan dengan cara pemuatan nilai subtantif ajaran Islam dalam konteks Indonesia sekurang-kurangnya mempunyai dua argumen sebagai berikut:

Pertama, didalam sumber primer ajaran Islam, al-Qur'an dan as-Sunnah tidak ada keharusan bagi ummat Islam untuk membentuk negara Islam, yang terpenting adalah adanya negara yang melindungi dan menjamin kebebasan untuk menjalakan ibadah yang sesuai dengan ajaran Islam. ${ }^{15}$ Kedua, tokoh-tokoh Islam Indonesia pada masa lalu telah berjuang melalui jalur konstitusi yang demokratis, dan menawarkan Islam sebagai dasar negara, ${ }^{16}$ tetapi hasil kesepakatan yang di peroleh melaui proses politik yang demokratis pula, yakni menetapkan Pancasila sebagai dasar negara. ${ }^{17}$ Maka kesepakatan itu harus diterima sebagai mitsāqan ghalidzà (kesepakatan luhur) yang harus dijaga dan dilaksanakan secara konsekuen.

NB: Tulisan ini merupakan bagian dari tesis saya yang berjudul : Penerapan Qanun Aceh di Kota Subulussalam "Kajian Atas Qanun Nomor 12, 13 dan 14 Tahun 2003"

\footnotetext{
${ }^{13}$ Nadirsyah Hosen, "Religion and the Indonesian Constitution ..., 426.

14 Muh. Mahfud MD, Jiwa Syariat Dalam Konstitusi Kita, dalam Masdar Farid Mas'udi, Syarah Konstitusi UU 1945 Dalam Perspektif Islam (Jakarta: Pustaka Alvabet, 2011), XVII.

${ }^{15}$ Lihat Pasal 29 ayat 2 UUD 1945 tentang kebebasn untuk memiliki atau memeluk agama yang mereka anut atau percayai dan kewajiban memiliki agama yang di anut dan juga beribadah sesuai agama yang mereka percayai. Hal ini berrarti tidak ada tempat untuk ateisme seperi halnya kebebasan beragama Amerika dan negara-negara Uni Soviet.

${ }^{16}$ Martin van Bruinessen, "Islamic state or state Islam? Fifty years of state-Islam relations in Indonesia", Ingrid Wessel (ed.), Indonesien am Ende des 20. Jahrhunderts, Hamburg: Abera-Verlag, pp. 19-34, 4.

17 Arif Hidayat, "Formalization Of Sharia Law In Indonesia (A Constitusion Perspective)", Proceeding - Kuala Lumpur International Business, Economics And Law Conference Vol. 3. December 2 - 3, 2013,78 .
} 